\title{
Política exterior do Governo Lula: o desafio africano
}

\section{JOSÉ FLÁVIO SOMBRA SARAIVA*}

O objetivo do artigo é o de avaliar, no eclipse do governo dirigido por Fernando Henrique Cardoso e na chegada ao Palácio do Planalto do novo governo liderado por Luís Inácio Lula da Silva, as possibilidades de relançamento da política africana do Brasil. Herdeiro de uma década de baixa densidade na política do Brasil para a África, o novo mandatário terá pela frente o desafio da revalorização desse capítulo essencial da inserção externa do país. A transição governamental, ao sugerir o esforço de revisão de políticas adotadas em várias áreas, é ambiente propício para passar em revista o saldo acumulado. A partir desse diagnóstico, pretende-se sugerir uma pauta de itens para a retomada da dimensão atlântica da política externa brasileira.

O diagnóstico e as propostas para a ampliação do relacionamento do Brasil com a África não podem ser realizados sem se levar em conta o marco maior da própria política externa. Nesse sentido, a política africana do Brasil será observada sob um contexto mais amplo, o dos modelos de inserção externa do Brasil nas últimas décadas, sem o qual não se podem perceber certas dificuldades vividas pelo país com o outro lado do Atlântico Sul, em especial nos anos 1990 e no início do novo século.

Em segundo lugar, vale buscar leitura apropriada do meio internacional, de seus constrangimentos e possibilidades. Sem essa dimensão, padeceria o estudo presente da moldura que o envolve. As relações internacionais pós-Guerra Fria promoveram novos desafios para as políticas exteriores dos Estados, desde aqueles derivados da fluidez do sistema internacional até os resultantes da própria erosão de papéis clássicos do Estado.

Finalmente, a discussão sobre a política africana do Brasil não pode prescindir do debate em torno da marginalização da África nas relações internacionais contemporâneas. Esse dado trouxe inquietações ao processo decisório brasileiro, ao acrescentar dúvidas e discussões em torno das oportunidades e da funcionalidade de uma política ativa para aquele continente. A compreensão de algumas posições tíbias brasileiras nos anos recentes pode ser imputada ao próprio isolamento internacional a que a África foi submetida. 
Essas três dimensões ganham relevo na construção do argumento central do texto: o de que é possível relançar uma política mais ativa e construtiva para o continente africano. Sugerir essa linha de reflexão e de ação expõe a vontade de articular o esforço de compreensão, mais próprio ao espaço acadêmico, com o esforço da responsabilidade social, âmbito próprio ao da política.

\section{Urnas e política externa}

No ensejo da posse do novo governo brasileiro, em janeiro de 2003, ante as expectativas que se criam no seio da sociedade brasileira em torno de capítulos cruciais à inserção internacional do país no nascedouro do novo século, urge repensar a política externa. As lições das urnas parecem sugerir não apenas a reprovação do modelo de modernização gestado no Brasil no início dos anos 1990, mas igualmente da derivada relação externa desse modelo.

A formulação e a implementação da política exterior vêm sendo postas ao escrutínio, nas mais diversas faixas de percepção da sociedade civil. Criticada por sua baixa criatividade conceitual e por relativamente fraca capacidade operacional, a política externa do Brasil está deixando de ser mero assunto de Estado para ser também uma matéria da nação. ${ }^{1}$

Nesse sentido, o espaço público vem ganhando força, ainda que de forma reativa, no âmbito das discussões das relações internacionais no Brasil. O debate vem se qualificando de forma célere, para surpresa dos que imaginavam deter o monopólio da discussão. Participando cada vez mais dos debates em torno do seu destino como nação, a sociedade brasileira vem, de forma madura, decidindo suas opções externas, a incluir essa dimensão no processo de escolha dos seus governantes.

A abertura desses horizontes societais das relações internacionais vem permitindo associar o espaço comum (das ruas, das praças e do cotidiano) ao espaço político (o do poder decisório), na inédita criação do espaço público. O coração do funcionamento democrático das instituições vem, portanto, beneficiando-se do aprendizado da reflexão acerca do lugar do Brasil no mundo. A sociedade brasileira vem entendendo, pela via da pedagogia democrática, que deve tomar conta do seu destino, para que aventureiros não capturem seu devir.

As discussões realizadas em foros os mais diversos, como aqueles que alinharam posições em 2001 e 2002 nos grandes eventos organizados pelo Congresso Nacional sobre a formação da Área de Livre Comércio das Américas (Alca), ou mesmo a mobilização da Comissão Parlamentar Conjunta do Mercosul ao procurar envolver, na superação do seu imobilismo, as universidades e outros atores da sociedade civil no contexto das discussões acerca dos caminhos do processo de integração sub-regional, são exemplos notórios do despertar da letargia. ${ }^{2}$ 
A efervescência nas discussões das associações patronais, dos setores mais ativos da burguesia nacional ou de setores sindicais atentos aos impactos arrebatadores da economia política da globalização, fez do tema da inserção internacional do Brasil um dos aspectos cruciais nos programas dos postulantes à presidência da República na campanha de 2002. ${ }^{3}$ Em praticamente todos os programas eleitorais, e nas manifestações mais contundentes de alguns dos candidatos a chefe de governo, o tema internacional ganhou relevo todo especial, como se pode observar no caso de um dos candidatos eliminados no primeiro turno das eleições:

"O Brasil tem quatro grandes desafios simultâneos, um conectado ao outro. Não é possível separá-los nem que seja por retórica. Em primeiro lugar, o país não terá solução para os profundos desequilíbrios, alguns deles explosivos, se não voltar a crescer e se desenvolver. Um segundo ponto é que não é possível mais administrar as energias e tensões que estão se acumulando se não transformamos o modelo de distribuição de renda do país. Em terceiro lugar, nada disso será praticado se o Brasil não resgatar sua soberania em contexto internacional complexo. Em quarto lugar, tudo isso não será feito por ações individuais. Terá de haver uma grande participação da sociedade porque teremos que confrontar privilégios internacionais e locais muito poderosos". ${ }^{4}$

Múltiplas análises, publicadas em diferentes revistas especializadas, ademais de artigos de opinião em jornais e revistas de circulação nacional, chamam a atenção para a necessidade de rever o padrão de inserção internacional do Brasil diante dos novos desafios gerados pela globalização, pela interdependência global, pelas novas agendas, pelo protecionismo das potências avançadas, pelos Estados Unidos em sua inclinação unilateral e imperial, entre outros grandes temas. ${ }^{5}$

Essas percepções tornaram-se cada vez mais públicas entre os responsáveis no Partido dos Trabalhadores (PT), especialmente do grupo mais atinente ao assessoramento do novo presidente nos assuntos internacionais. O professor Marco Aurélio Garcia, responsável durante mais de uma década pela secretaria de relações internacionais do PT e acompanhante de Luis Inácio Lula da Silva na maior parte dos encontros do novo presidente eleito com líderes estrangeiros durante toda a década de 1990 e início da nova década, chamou a atenção recentemente para as relações entre política externa e vulnerabilidade externa:

"Vamos enfrentar um ambiente internacional muito complexo. Então nós temos que ter claro o seguinte: o Brasil tem um peso reduzido no mundo. É preciso adensar a nossa presença internacional. Para isso, temos que diminuir a nossa vulnerabilidade econômica externa. Isso passa, em primeiro lugar, por um novo desenho da política econômica. O que nós podemos fazer é dar mais musculação à presença brasileira no mundo. Esse é um processo lento e complexo, que acompanhará todo o desempenho de nossa política externa”. ${ }^{6}$ 


\section{Brasil e África: convocação à revalorização da dimensão atlântica da política exterior do Brasil}

Urge, nesse quadro de relações entre as urnas e a política externa, revisitar a tradicional política africana do Brasil, relativamente abandonada pelo governo de Fernando Henrique Cardoso. Para implementá-la, apenas uma nova forma cooperativa - na qual governo, empresários, setores políticos organizados e acadêmicos sejam convocados a pensar estrategicamente o futuro do continente africano - será capaz de engendrar saídas para as dificuldades do momento. Ademais, outros setores sociais, historicamente alheios ao processo decisório em matéria internacional - como os afro-brasileiros -, necessitam ser ouvidos sobre matéria que, embora de interesse societário, ainda se circunscreve ao viés prejudicial no trato da política exterior como assunto burocrático, de especialistas ou de profissionais da diplomacia.

Aprecia-se a idéia de que o parlamento nacional - que tem tido papel crescente e relevante nas discussões em torno da formação da Alca e mesmo do Mercosul - venha a retirar o assunto das nossas relações com os países ribeirinhos do Atlântico Sul do trono do príncipe e devolvê-lo ao povo. As razões de complexidade das relações intergovernamentais e os aspectos específicos que as caracterizam, associadas às visões derivadas do jurisdicismo obsoleto que vê o tema internacional como competência de discussão privada do Poder Executivo, não podem obliterar o debate público da política externa brasileira para a África.

O experimento da democratização, da socialização do debate acerca das possibilidades do meio internacional e do comportamento da política externa do país é dever da sociedade, a ser mediado por seus múltiplos agentes, entre os quais o parlamento. A transformação das relações internacionais nas últimas décadas, a torná-la mais difusa e a interpenetrar nações, Estados e culturas, gerou demanda entre os atores sociais e agentes econômicos por uma maior transparência na formulação das políticas externas nacionais, antes cercadas pela aura do segrego. A África não pode ser tratada como algo fora da sociedade brasileira, em torno da qual apenas resta observá-la, de binóculos, à distância marítima dos dois continentes.

Oportunidades, esquecimentos e relançamentos fazem parte da linha histórica de tratamento das relações externas do Brasil com a África. ${ }^{7} \mathrm{O}$ triângulo se move de forma ciclotímica, no compasso nervoso do tempo, a modular momentos múltiplos. O Brasil oscilou historicamente entre o amor incontido nas suas relações com algumas metrópoles européias em detrimento da África, mesmo diante do ocaso do colonialismo na África. O caso mais nítido foi a relação do Brasil com Lisboa, privilegiada por longo tempo em detrimento das possibilidades de um diálogo direto com outras partes do mundo de língua oficial portuguesa na África.

Houve, no entanto, rupturas importantes nas relações do Brasil com o continente africano, como aquelas, nos anos 1970, que levaram a posições ativas 
de reconhecimento rebelde de Estados recém-nascidos da luta emancipacionista de viés comunista, contra os interesses da potência hegemônica. $\mathrm{O}$ caso angolano, no contexto da independência de 1975, é emblemático da inflexão realizada pelo Brasil na África. ${ }^{8}$

Não é ingênua a imaginação de que uma política africana do Brasil possa ser posta em marcha, apesar dos constrangimentos do momento, diante dos meios escassos e do afastamento político e intelectual em relação ao outro lado do Atlântico. A oportunidade para debater sobre as relações do Brasil com esses países é ímpar, necessária, urgente. Deixa-se morrer um cabedal interno de conhecimento sobre a África. Encantados alguns formuladores de política exterior do Brasil pelos pólos do poder global, abandonaram eles uma das matrizes que confere identidade à inserção do Brasil no mundo: a relevância estratégica, cultural, econômica e identitária da África. Mas ainda se pode recuperar o tempo perdido.

Os primeiros gestos das lideranças intelectuais que conhecem o assunto internacional no Partido dos Trabalhadores parecem indicar alguma sensibilidade para a convocação de um política africana renovada. Marco Aurélio Garcia sugeriu isso publicamente, ao enumerar os principais focos da ação externa do novo chanceler - como reforçar a dimensão sul-americana, mercosulina e argentina nas nossas relações externas; discutir criticamente a ALCA e as relações bilaterais com os Estados Unidos, México e Canadá; reforçar parcerias estratégicas na Europa especialmente com Alemanha, França, Espanha e Portugal - e fora da Europa como aquelas já ensaiadas com a China, a Îndia, a Rússia e a própria África do Sul. A inclusão da África do Sul nessa linha de parceiros estratégicos não é nova, mas acrescenta o influente quadro intelectual do PT: "Para completar, é preciso ter uma política africana". ${ }^{9}$

\section{Uma nova política africana do Brasil: superando os limites de um modelo obsoleto de política exterior}

Há limites reais para o relançamento de uma política africana do Brasil no seio da qual se desenvolveria um gesto de atenção cooperativa com os parceiros do outro lado do Atlântico. Os constrangimentos gerados pela adoção de um modelo econômico perverso na última década, marcado pela desidentificação da nação e pela incursão no terreno movediço das vulnerabilidades criadas pela alienação do patrimônio nacional a grandes companhias internacionais, inibiram a vontade política dos governantes, limitaram investimentos materiais na economia atlântica e reduziram a criatividade diplomática para os assuntos africanos.

Basta ver a evolução do quadro de diplomatas brasileiros no exterior para verificar a diminuição gradativa da importância estratégica do Brasil para a África. Ao contrário da tendência de ampliação do número de diplomatas acreditados junto aos demais Estados amigos, a África esteve na contramão desta tendência. 
As três dezenas de diplomatas profissionais que atuavam naquele continente, nas diferentes missões diplomáticas no início da década de 1980, foram reduzidas em cerca da metade. Foram deslocados diplomatas brasileiros da África para outros continentes e áreas de maior prioridade, como a própria Europa, a América do Sul e os Estados Unidos.

As relações do Brasil com a África nos anos 1990 e no início do novo século foram ajustadas a um contexto atlântico, entendido pelos formuladores da política externa como menos relevante à inserção internacional do país. Para trás ficaram os anos de ativa cooperação mútua e de empreendimentos comuns sustentados na determinação do Estado brasileiro em desenvolver projetos econômicos voltados para o desenvolvimento da África, diversificando os parceiros do comércio internacional do país e subtraindo as dificuldades geradas pela vulnerabilidade energética dos anos 1970 e parte da década de 80.

A própria sociedade civil brasileira perdeu, nos últimos tempos, parte do encantamento nas possibilidades construtivas de uma forte presença brasileira na África. O silêncio sobre o que acontece na África no debate político nacional, nas universidades e na imprensa são indícios do desinteresse generalizado pelo outro lado do Atlântico. A essa perda da vocação atlântica correspondeu desmobilização diplomática voltada para a projeção da imagem do Brasil como um poder tropical e industrial, mas que um dia fora também uma colônia.

Do lado africano, quatro décadas depois do início das independências, o continente encontra-se em profunda crise, de contornos manifestos, mas de explicação controversa. Nem as políticas de ajustamento estrutural preconizadas pelo Banco Mundial e pelo Fundo Monetário Internacional, nem os processos de ampliação da democratização dos sistemas políticos têm sido suficientes para enfrentar a profundidade dos problemas econômicos, políticos e sociais que o continente enfrentou na década passada e enfrenta nos primeiros anos do novo século. As reações endógenas à marginalização internacional do continente, como a recentemente criada União Africana e a afirmação da iniciativa da Nova Parceria para o Desenvolvimento Africano (NEPAD), a partir de 2001, ainda que visionárias, ainda não demonstraram plenamente seus potenciais de reverter o ostracismo africano. ${ }^{10}$

Também contribuiu para o afastamento do Brasil em relação à África um certo zigue-zague na política externa brasileira, movida por parâmetros oscilantes, em uma espécie de "dança de paradigmas". ${ }^{11}$ O país parece ter transitado entre parâmetros confusos, em política externa, nos anos 1990. Desde os equívocos de substância - como o da apresentação da abertura econômica, da estabilidade monetária e da democracia como vetores de política externa, mesmo sabendo que tais vetores nunca serviram a Estados maduros como vetores externos, passando pela aplicação a crítica de políticas importadas de rigidez fiscal, a retirar o Estado dos investimentos produtivos, a contrair salários, a privatizar empresas públicas, 
vendendo-as às companhias estrangeiras para arrecadar dólares e pagar a dívida externa - até os equívocos de meios - como a crença kantiana e idealista da diplomacia de Cardoso nos foros multilaterais -, todos esses equívocos foram pagos com uma conta elevada no campo da ação do Estado brasileiro na África, embora não apenas naquele continente.

A África ficou fora do norte da política externa do Brasil nos anos 1990. O Brasil se deixou contaminar pela interpretação ingênua das relações internacionais kantianas, em torno das quais as saídas para a modernidade estavam no multilateralismo e no esforço da construção de uma agenda global consensual e na regulação de temas globais como o liberalismo econômico, o meio ambiente, os direitos humanos, entre outros. Essa confusão conceitual levou ao abandono de ricos caminhos anteriores já trilhados pelo Brasil na África, emanados pelo modelo de substituição de importações e da política de promoção de exportações. Ao confundir meios com fins, a política exterior brasileira perdeu sua racionalidade anterior.

A reversão do comércio exterior, amparado no preconceito de que certo protecionismo do mercado interno emperrava o crescimento econômico e de que o comércio exterior perdera sua função de gerar saldos, mataram as matrizes que davam materialidade à política atlântica do Brasil. Associada a essa dificuldade estava o fato de que se gerara uma extraordinária expectativa nas potências avançadas por parte de diplomatas e negociadores brasileiros acerca da vontade reformadora do sistema multilateral, a conduzir o Brasil para uma modernidade que em muito distava do padrão de relacionamento comercial externo que embalara os "anos dourados" da política africana do Brasil. ${ }^{12}$

Se esses cálculos externos estiveram equivocados - como se percebe em momento de escrutínio eleitoral do modelo de inserção internacional - eles reverberaram duramente na política externa do Brasil e tiveram impactos perversos e alienantes em relação às políticas africanas do país. A reversão se fez presente em todas a áreas, da empresarial - de onde o Estado retirou sua sinalização de prioridades a projetos robustos de parcerias africano-brasileiras no campo do desenvolvimento econômico da África - àquelas de concertação política e aproximação cultural entre os povos das duas margens do Atlântico Sul.

A erosão do modelo universalista de inserção internacional do Brasil substituiu a África pelo Mercosul, quando o ideal teria sido manter a África e abrir a brecha do Mercosul. A história recente desse último processo de integração está a demonstrar, em suas dificuldades do momento, que teria sido necessária a permanência de um canal de comunicação mais vivo com os países ribeirinhos africanos, com ênfase àqueles de língua oficial portuguesa e a alguns parceiros que se mantiveram relevantes para o Brasil.

Para tal teriam sido necessárias visões mais largas acerca das nossas necessidades internas e das possibilidades abertas no plano externo. A retomada 
nos últimos anos, mesmo sem explícito estímulo governamental, de uma crescente pauta comercial com os países africanos - como o que se verifica em relação à Nigéria (com a qual o Brasil chega à marca de quase US \$ 1 bilhão de intercâmbio comercial nos últimos anos) - demonstra o quanto teria sido necessária manter uma plataforma de operações na região. O retorno está sendo caro, do ponto de vista material, e ainda tíbio, sob o ângulo das vontades políticas envoltas no processo decisório.

Amparados na matemática realista de certo declínio nos intercâmbios materiais da década passada, os pessimistas ainda insistem que não temos o que fazer na África. Aproximar-se ao continente africano significaria, para os niilistas, o abraço da morte ou o explorar das minas escassas, improdutivas, exauridas pelo tempo de exploração. Ou mesmo que não há salvação na África, dominada pelo círculo perverso da história de alienação vinda de fora e da própria auto-alienação.

Há outros observadores, dentro e fora do Brasil, para os quais pouco importa a presença da língua portuguesa na África. Para esses, a própria estratégia da preservação da língua falada pelo Brasil na África deveria ser repensada, diante da sua baixa eficiência econômica e política. Ao ser instrumento impeditivo da própria comunicação no contexto regional de alguns desses países, a língua portuguesa lembraria um passado colonial a ser esquecido, diante da modernidade construída pelo acesso à língua inglesa, em especial.

Para tais alarmistas, o Brasil não tem nada a fazer em países como Moçambique. Lá - lugar no qual a língua de Camões e de Machado de Assis, mas também de Pepetela e outros africanos, traria certa desvantagem em um ambiente regional dominado pelos anglófonos - o Brasil não teria mais lugar, a avaliação dos pessimistas. País que tem a África do Sul como seu principal parceiro econômico, recebendo atualmente cerca de $40 \%$ das suas importações e exportando cerca de $15 \%$ dos seus produtos para aquele país, Moçambique seria o exemplo da situação esdrúxula de uma presença cultural brasileira inócua e da evidência da perda do prestígio da língua portuguesa na África.

O mesmo se diria, nessa visão, em relação à Guiné-Bissau, incrustada em seus vizinhos francófonos. Para além da África, na Ásia estaria o paradigma da desimportância da presença da língua portuguesa, uma vez que o Timor Leste independente ainda abriga uma grande maioria da sua população não alfabetizada em língua portuguesa.

Nesse capítulo os pessimistas se confundem, de forma ridícula, com os arautos do mundo único, dominado pela ausência de antinomias e diversidade. A presença do Brasil na África de hoje, ao contrário do que pensam, é fator de diversidade e de construção de um olhar próprio sobre o mundo. Essa presença não pode ser apenas um fator de prestígio político e cultural, ou mesmo o redesenhar, em tempos contemporâneos, dos velhos mitos sobre a presença portuguesa do ultramar. O Brasil não pode estar nessa empreitada apenas para não perder sua 
influência, ou porque sua presença na região se mantém por osmose ou mesmo porque a presença retórica custa pouco para o orçamento nacional.

Ao contrário de tudo isso, o Brasil tem um lugar na África. Conquistou esse lugar de forma própria, sem a batuta de outro maestro, com seus próprios meios, em um esforço da sociedade brasileira no seu conjunto, à busca de alternativas de inserção internacional e de correção de dívidas históricas com as mulheres e homens do outro lado do Atlântico. Isso não é ser romântico ou saudosista. Ao contrário, é atuar de forma altaneira acerca dos destinos da nação e das suas possibilidades no campo da ampliação do prestígio consentido e natural no Atlântico Sul.

\section{Razões para uma renovada política africana do Brasil}

E por que razões tem o Brasil que lançar uma renovada política africana no início do novo século, no contexto de mudança governamental em curso? Algumas pistas foram aqui fornecidas, mas necessitam ser melhor organizadas na forma de apenas cinco pontos essenciais, mas sujeitos ao debate aberto pela sociedade brasileira e pelo processo decisório nacional em matéria de política exterior. As questões estão, como devem estar, abertas ao debate societal.

Em primeiro lugar, o Brasil contemporâneo é herdeiro de uma rica tradição, que gerou frutos importantes para a inserção internacional do país, na forja de parcerias múltiplas, consonantes com a tolerância da nossa sociedade, o que tampouco exclui manifestações de racismo explícito em vários casos específicos. Mas tem o país uma experiência de recepção de todos que um dia aportaram as areias da Terra de Pindorama. Dessa tradição deriva nossa vocação universalista em política exterior. Estar na África é, portanto, estar prestando contas internas, naquele aspecto que faz os brasileiros ímpares e originais no seio da comunidade internacional.

Ademais, como bem a história vem demonstrando, não se podem concentrar relações externas do Brasil em pólos únicos, em detrimentos de outros, apenas pela razão do poder hegemônico, imperial ou especulativo que tais centros exercem. As relações internacionais não se realizam apenas na realpolitik nem no ambiente dos interesses imediatos. A dimensão africana da política externa do Brasil não pode se circunscrever, pela sua própria dinâmica interna, apenas aos fatores da materialidade.

A política africana do Brasil deve ter estatuto próprio, identidade que a torna singular, no emaranhado de interesses múltiplos do Estado e da sociedade brasileiros, no ensaiar de suas possibilidades externas. Temos que saber que em África temos mais a oferecer que a receber, em termos materiais, para podermos receber mais que oferecer, no plano da imaterialidade. Mas tudo isso deve ser feito sem que o paternalismo entre no jogo. 
Em segundo lugar, temos uma dívida histórica com a África a demandar uma política específica, pública e legitimada pela sociedade brasileira, por intermédio de instituições como seu parlamento, suas universidades, suas empresas e a opinião pública, em geral. A África é lugar privilegiado de formação da brasilidade, curtida e urdida ao longo do longo compasso do tempo. ${ }^{13}$ Os dois lados do Atlântico Sul abraçam-se em era geológica remota, compondo um mundo uno. A África ocupou papel cêntrico na formação da sociedade e da economia do Brasil. A escravidão de africanos no Brasil, para a grande maioria dos historiadores brasileiros, foi o coração que fez pulsar a organização social da colônia portuguesa nos trópicos e se tornou o amálgama da organização do Estado imperial no século XIX.

Apesar dos laços encerrados em certo momento e do silêncio que imperou nos escassos contatos atlânticos em grande parte do século XX - reforçados pelo sistema escolar brasileiro que ajudou a cristalizar o afastamento da África, congelando o continente ao tempo da escravidão e reduzindo a presença da África na história do Brasil, em livros afônicos de brasilidade - a África permanece como uma lavra fundadora da brasilidade, queiram ou não os críticos de Gilberto Freyre.

Uma boa forma de iniciar as comemorações dos duzentos anos do Brasil independente em 2022, e que se aproximam rapidamente sob o manto da indiferença, seria pautar uma série de iniciativas para valorizar essa vertente da nossa formação pela via da celebração de uma nova política africana, a ser também exposta, daqui a vinte anos, como uma obra de reconciliação interna e de expressão da vontade política com o outro lado do rio chamado Atlântico.

Ao fazer esse exercício criativo, note-se que não se terá que desenhar apenas uma política africana, mas várias, de região a região, de povo a povo, de nação a nação, na diversidade que compõe o xadrez africano, de uma forma mais sofisticada em relação a hoje praticada. Esse esforço terá efeito pedagógico interno uma vez que estaremos a recordar o fato de termos não apenas uma África dentro do Brasil, mas múltiplas Áfricas, como nos lembra o maior africanista brasileiro da atualidade, o imortal Alberto da Costa e Silva (também um expoente da fase dos "anos dourados" da política africana do Brasil), em seu livro que acaba de ser lançado, A manilha e o libambo; a África e a escravidão, de 1500 a 1700:

"Disto, da enorme diversidade de maneiras de fazer, pensar e viver, que torna a África várias Áfricas, creio que dei boa notícia. No seu dia-a-dia, um abexim pode ser tão diferente de um ijexá, e este de um pende, e um pende de um mandinga, e um mandinga de um soto, quanto um alemão de um andaluz e um húngaro de um escocês. É bem verdade que há certos gestos, comportamentos, símbolos, crenças e valores que são comuns a grandes áreas do continente ou a todo ele. É possível que este povo tenha aprendido com aquele a ter no gonguê ou no agogô o instrumento com o qual se anuncia a presença do rei, e que venham do Egito islâmico os grandes guarda-sóis que, em boa parte da África subsaariana, giram 
sobre as cabeças dos que se têm por grandes. Mas, se a história de Lat Sukaabe guarda parecença com a do Sundiata e de outros reis fundadores, se tantos emblemas de poder e fé são semelhantes e se até mesmo certas instituições políticas se repisam a grande distância, não há esquecer que as mãos humanas, por toda a parte, repetem as mesmas formas essenciais para responder aos desafios das mesmas necessidades, como mostram os pouquíssimos contornos que pode ter a moringa. Li, faz muitos anos, já não sei se em Hegel, que não passariam de trinta e poucos os enredos que nos cabe viver: o de Ulisses, o de Penélope, o de Fedra, o de Argan, o do Quixote, o de Sancho Pança, e assim por diante. Não seriam mais numerosos os entrechos de que se fazem as histórias dos povos. A riqueza da existência não se deveria apenas à mescla dessas intrigas, mas também às diferenças de alma e de momento, e por isso Capitu e Bentinho não copiam nem negam Desdêmona e Otelo. Tampouco a história de Songai reproduz ou contradiz a do Mali ou a de Roma, ainda que as três se desenhem com os traços do império.”14

Em terceiro lugar, o relançamento da política africana do Brasil não seria apenas um ato de fé, mas o resultado de dois cálculos: um político e outro econômico. Politicamente, ela serve para reforçar a idéia de que o Brasil ainda tem um projeto cooperativo Sul-Sul, mas em outras bases, a engendrar alguma liderança nas novas rodadas de negociação de temas globais, na reformulação do Conselho de Segurança das Nações Unidas, na busca de parcerias estratégicas no Sul junto a países como a África do Sul, Índia e China. Além disso, uma política africana bem concertada com seus parceiros do outro lado pode constituir instrumento de barganha na vontade de reorientação do eixo diplomático de temas como o terrorismo para outros temas, mais construtivos e de interesse mútuo do Brasil e do continente africano, como o desenvolvimento sustentável e a cooperação Sul-Sul.

Economicamente, o relançamento de uma política africana serviria de elemento constitutivo no esforço do redesenho da inserção internacional do Brasil, em nítida crise de identidade no momento atual. Em contraste com a inserção internacional marcada pelo triunfalismo liberal, como discutido anteriormente, a África serviria ao movimento de aproveitamento de brechas estruturais na ordem internacional e de reforço na retomada de um modelo de inserção internacional de bases mais nacionais e voltado para o desenvolvimento interno sustentável, gerador de empregos e produtivista, mais que financista.

Para tal seria necessário que iniciativas fossem geradas nas "brechas estruturais” 15 que necessitam ser urgentemente preenchidas por políticas mais inteligentes e assertivas. Refiro-me aos espaços que se abrem, no coração da crise internacional do momento, pelos foros da tecnoburocracia das próprias instituições internacionais controladoras do poder global, como o FMI, o Banco Mundial e o BIS - Bank for International Settlements. Diante da vulnerabilidade dos modelos econômicos adotados na década passada por vários países do Sul, entre eles o Brasil, e à luz da pressão que se faz notar no campo interno dos 
Estados, particularmente no que se refere à crescente incapacidade dos governos de lidar com um conjunto de políticas sociais, econômicas e de tratamento de conflitos, há uma brecha aberta na revisão crítica acerca dos efeitos perversos de uma ordem internacional sustentada na unilateralidade dos ganhos dos setores financeiros.

Mas a construção de uma agenda positiva com a África - e com os países africanos de língua portuguesa, em especial - dependerá da capacidade de agir juntos, nos planos interno e externo dos Estados, de forma a mobilizar, de maneira nova e criativa, em favor do reconhecimento do fracasso de receitas aviadas em consensos como o de Washington. Significa também reaprender a enfrentar os fortes da ordem global, como visto naquele gesto ensaiado pelo Brasil na última Conferência Ministerial da Organização Mundial do Comércio, em Doha, em novembro de 2001, no que se refere ao tema da quebra de patentes de medicamentos necessários ao combate da AIDS.

Esses esforços recolocariam a África em horizonte mais próximo da política externa do Brasil, bem como de outras áreas de interesse relegadas, na perspectiva do aproveitamento de um capital político que o Brasil ainda possui do outro lado do Atlântico. E isso se coaduna com um projeto de política exterior mais universalista e adaptado às circunstâncias atuais.

Em quarto lugar, há uma vontade africana em dialogar com o Brasil. A recente formação da União Africana bem como da NEPAD, aqui já referidas, são fatores de animação interna no continente. O desafio do crescimento econômico na taxa de $7 \%$ anual para os próximos 15 anos expõe o desafio e a dimensão corajosa da NEPAD. A redução pela metade da taxa de pobreza absoluta até 2015 é meta na qual o Brasil pode compartilhar sua experiência e suas dificuldades com a África. A incorporação de todas as crianças, em idade escolar, nas escolas primárias, outro objetivo alvissareiro dos africanos na valorização dos seus desafios, deveria contar com a colaboração do Brasil, que caminha nos mesmos trilhos da superação dos dramas da desnutrição, da pobreza e da escolarização das crianças.

Ao mesmo tempo, o entusiasmo com o diálogo direto com o Brasil, no plano do compartilhar de experimentos no campo do desenvolvimento sustentável, foi a marca da exposição do grupo dos 15 embaixadores africanos, que compõem o Grupo dos Embaixadores e Chefes de Missões Africanas em Brasília, em seminário internacional organizado na Universidade de Brasília, no dia 22 de outubro de 2002. As palavras do embaixador da Nigéria, Josef Sookore Egbuson, falam por si mesmas:

"And in the ensuing process of globalisation, with the attendant challenges, we believe that Brazil would be most helpful in narrowing the huge division between rich and poor countries by generously availing and investing in knowledge and technology highly adaptable to the unique circumstance of Africa and which will avail a future where politics, economy and ethics will not be dichotomised and 
sanctify of human life would take premium place. However, such disposition should not be limited to the Economy, and must necessarily include sustainable development in favour of stability, democracy and responsible macroeconomic management as the prevailing condition of neglect and poverty represents a permanent challenge to the good functioning and viabililty of social political institutions in Africa."

Em quinto lugar, e finalmente, há algo particular às novas relações lusobrasileiras que deve ser utilizado na reaproximação aos países africanos de língua oficial portuguesa. O novo ambiente deriva de substrato inédito, alvissareiro, na nítida superação, a partir de meados da década de 1990, dos tempos nos quais as relações entre Portugal e Brasil não ultrapassavam senão os limites do formalismo improdutivo. A nova engenharia da atuação bilateral entre os dois países traz impacto para o projeto de relançamento da política africana do Brasil.

Os investimentos portugueses no Brasil, o turismo crescente lado a lado, a presença portuguesa nas comemorações da viagem de Cabral, a consolidação dos tratados assinados em Porto Seguro em abril de 2000, entre outros aspectos, parecem indicar uma mudança de rumo, modificando-se a letargia do passado. À estratégia portuguesa de internacionalização da economia correspondeu crescente presença lusa no mercado brasileiro. A revalorização menos eufórica e mais pragmática do capital político alicerçado pela importante presença da comunidade portuguesa no Brasil e de uma crescente comunidade brasileira em Portugal serve para uma aproximação mais franca e direta entre as duas sociedades.

A realização em Brasília da Quarta Conferência de Chefes de Estado e de Governo da Comunidade dos Países de Língua Portuguesa, no final de agosto e início de setembro de 2002, foi ocasião alvissareira para passar em revista o breve percurso histórico dessa infanta instituição, dotada de personalidade jurídica internacional, e para investigar acerca das suas potencialidades em futuro próximo. As novidades da Conferência de Brasília foram muitas, com grande destaque para a inclusão do seu oitavo membro, o Timor Leste, abrindo uma franja asiática para uma instituição internacional tingida pela baixíssima visibilidade interna nos Estados membros e por quase imperceptibilidade perante a comunidade internacional.

Destaca-se o relançamento da estratégia conjunta dos chefes de Estado e de governo no sentido da redução das barreiras internas impostas pelas legislações nacionais, ciosas da abertura dos seus portos e aeroportos à livre circulação dos 200 milhões de cidadãos do clube da língua portuguesa. Reforça-se a cooperação técnica na área da saúde, com os acordos voltados para ações conjuntas de prevenção, diagnóstico e assistência aos doentes contaminados pelo HIV. A idéia da transferência de tecnologia entre os países-membros bem como a formulação de políticas de acesso aos medicamentos é altamente positiva. Os seis acordos de Brasília sinalizam, assim, o possível ou o minimo minimorum que permite ir dando vida à CPLP. 
A CPLP vem, no entanto, trilhando um caminho tortuoso desde sua criação em 1996, no Palácio de Belém, em Lisboa. A instituição parece não haver tido tempo ainda para se libertar das ambigüidades criadas pela convivência histórica de sete países, agora oito, com projetos e interesses distintos no projeto comunitário. Brasil e Portugal nem sempre coincidiram nas suas intenções de convergir políticas em favor da valorização da CPLP. Os países africanos, por sua vez, mais esperam do que podem oferecer aos esquemas de funcionamento e de financiamento da instituição.

O Brasil expõe uma dificuldade de origem, transportada para o momento atual, em suas escolhas políticas no mundo da lusofonia. O surgimento e o desenvolvimento da CPLP coincide com um ciclo de retraimento das relações comerciais, diplomáticas e estratégicas com os países africanos. Há problemas do lado africano também. Angola, Cabo Verde, Guiné-Bissau e São Tomé e Príncipe não nutrem a mesma visão acerca do sentido político e econômico da CPLP. Uns querem valorizar apenas a língua enquanto outros desejam fazer da CPLP uma agência de fomento ao desenvolvimento.

O fato é que a inserção de cada um desses países na instituição está plasmada pela impotência e pela frustração. Estados que derivam seus projetos de modernidade de um processo tardio de descolonização atabalhoada, alguns deles estão ainda esgarçados pelas seqüelas deixadas por guerras fratricidas ou desinteligências domésticas que comprometem a transformação positiva na direção do desenvolvimento econômico, social e da democratização das sociedades. Países que contextualizam suas políticas exteriores em meio a tragédias sociais e políticas tão graves não possuem peso relativo no cenário global. A redução dos mesmos à mera peça marginal no xadrez das relações internacionais pós-11 de setembro faz com que a concertação diplomática, também um dos objetivos da CPLP, não encontre ambiente propício para sua realização prática.

Há um ponto nevrálgico na CPLP, que atinge Portugal e o Brasil, em especial: uma certa ausência de conteúdo político e econômico nas formulações e práticas da instituição. Dessa crítica advém um rosário de reclamos com relação à dinâmica de trabalho e aos financiamentos de projetos. Os chamados projetos de pontos focais - como aqueles voltados para o combate ao HIV/AIDS e o da formação dos centros regionais de excelência em desenvolvimento empresarial e de administração pública - são, ainda que relevantes, limitados em relação ao que pode ser feito, mesmo em período de vacas magras.

Em outras palavras, espera-se que o momento midiático da Conferência de Brasília não tenha apenas encapsulado a CPLP a poucos minutos de glória. Seria trágico que não se aproveitasse a oportunidade para discutir a reinserção internacional dos países do Sul no contexto global pantanoso de hoje. Seria lamentável que apenas pululassem na imprensa local e internacional, para depois desaparecerem no compasso do esquecimento gradual, os encantos das sociedades que, nas várias 
partes do mundo, empunham a língua portuguesa como sua forma historicamente construída de pensar e educar seus filhos e filhas. Seria desastroso, mesmo no campo da língua portuguesa, que não se chegasse a um consenso final acerca do eternamente postergado Acordo Ortográfico da Língua Portuguesa, um dos projetos iniciais, e mesmo anterior à CPLP. São esses alguns dos novos desafios do novo presidente da República, no capítulo da política africana do Brasil, a serem enfrentados de forma determinada e consentida com a sociedade brasileira.

Nesse sentido, a articulação luso-brasileira é elemento essencial à construção de uma plataforma atlântica, cooperativa e utilitária, na articulação dos projetos pela via da troca de experiência na África, direta, mediando negócios e interesses, valorizando tanto a língua quanto as oportunidade econômicas. Afinal, a retórica não resiste à ausência de projetos. E, seguindo o ritmo da crítica aos equívocos de substância e aos equívocos de meios, sugere-se maior prudência ao Brasil e aos seus parceiros de língua portuguesa no que concerne às interpretações do meio internacional. Ambas as linhagens de equívocos não sacrificaram, no Brasil, apenas a política africana, mas nos levaram a um certo sentimento de infantilização e precariedade, pouco condizente com o destino histórico de um país continental, cheio de opções adormecidas. Mas há tempo para refazer a história. Vale incluir a África nos nossos ensaios de esperança.

\section{Alguns itens para uma agenda revigorada de iniciativas para a África}

Ao concluir, após o diagnóstico, a avaliação e as sugestões conceituais aqui apresentadas, creio essencial propor uma agenda construtiva para a retomada da política africana do Brasil. Elas estão aqui enumeradas em forma de itens a serem apreciados, em torno do debate público, democrático, no seio da sociedade e do processo decisório da política externa do Brasil.

Esses itens são apenas o início de uma série de aspectos propositivos que necessitam ser melhor detalhados. Eles estão didaticamente organizados em torno de dois campos: a) o das iniciativas estruturais, a envolver movimentação estratégica no campo decisório; e b) o campo das iniciativas conjunturais, cuja realização se imagina mais curta no tempo, embora estejam articuladas à dimensão estratégica.

No plano estratégico, o desafio do novo governo deverá ser:

- o de prover uma nova concepção no tratamento da política africana, por meio da retomada de uma "política global para a África” (embora não nos moldes das décadas de 1970 e 1980), mas a substituir o limitado enfoque das “opções seletivas”, registro da década de 1990 e início da década atual; ${ }^{17}$

- o de incluir a política africana na redefinição, no plano global, da mudança do "paradigma do liberalismo desenfreado", adotado em boa 
parte da década de 1990, para o paradigma da "política externa logística”, ${ }^{18}$ apenas recentemente ensaiada, voltada, portanto, para o desenvolvimento endógeno, para a valorização da dimensão da produção industrial, do fomento a uma certa infra-estrutura para ação da sociedade nacional no plano externo, a incluir uma ação de mais vontade política na reaproximação com a África;

- o de dotar a política africana de uma dimensão infra-estrutural - no plano da inteligência, por meio do estímulo ao estudo acadêmico e aplicado acerca das novas possibilidades criadas na África por iniciativas como a NEPAD e a União Africana; e no plano material, por meio da forja da coalizão empresarial-governamental no sentido da exploração de ações conjuntas em projetos de desenvolvimento na África;

- o de valorizar parcerias estratégicas com a África, especialmente no esquema de quadrilátero que inclui Pretória-Luanda-Lagos-Brasília, por meio da construção de agendas bilaterais e comissões mistas que venham a priorizar projetos estratégicos de desenvolvimento em ambos os lados do Atlântico, concertadas com sua sociedades civis e entendidos como prioridades nacionais;

- o de contribuir para a construção de confiança e liderança do Brasil na África, essencial às relevantes negociações internacionais que terão que ser entabuladas nas próximas décadas, em torno de temas de interesse comum como a desigualdade estrutural do sistema internacional, o protecionismo das economias centrais e a reforma das Nações Unidas;

- o de valorizar, por meio da aproximação gradual e cooperativa dos distintos processos de integração sub-regionais em curso nos dois lados, a idéia de um "espaço comum” (assemelhado ao que se vem buscando na América do Sul) - de relevância econômica, voltado para a celebração da paz e da democracia, mas igualmente de desenvolvimento social, econômico e político - no Atlântico Sul.

A esses seis eixos estratégicos correspondem outros dez movimentos conjunturais, de mais curto prazo, que podem ser engendrados imediatamente pelo novo governo, a partir da adoção e da ampliação dos aspectos estruturais mencionados. São, a saber:

- a valorização governamental da dimensão africana, particularmente interna ao Ministério das Relações Exteriores, por meio da criação de um Departamento da África com três divisões internas (África do Norte, África subsaariana, África de língua oficial portuguesa), independente do Departamento do Oriente Próximo, tendo em vista a 
enorme acumulação de tarefas existentes em campos e realidades tão diversas;

- o estabelecimento de uma logística operacional específica, por meio de tarefas "abre-portas" (como feiras, missões comerciais e culturais, bem como de escritórios comerciais e culturais nas capitais africanas de maior interesse estratégico para o Brasil), a envolver simbiose entre a área de promoção comercial do Ministério das Relações Exteriores com as áreas de exportação dos ministérios voltados para as áreas econômica e cultural, bem como com as universidades e grupos da sociedade civil interessados em participar de um esforço de ampliação da presença brasileira na África, a incluir setores dos movimentos afro-brasileiros;

- o melhor aproveitamento das 15 representações diplomáticas africanas na capital da República, que se sentem pouco mobilizadas, senão marginalizadas, em relação a outras áreas de representação diplomática junto ao governo brasileiro, por meio de consultas mais permanentes e seminários de trabalhos - aberto a intelectuais e empresários - no sentido de melhor dotar o gesto brasileiro para a África de inteligência política e racionalidade comercial;

- a articulação dessas áreas da logística operacional do governo na área de valorização da política africana, com grupos econômicos nacionais de alguma presença na África, para garantir uma pauta única de interesses comuns e de ação programática organizada, de forma a minimizar custos e ampliar as possibilidades de negócios e oportunidades;

- a posta em marcha de uma articulação, para a África, semelhante a atual existente entre a Comissão Parlamentar Conjunta do Mercosul e as universidades da região, de forma a dotar a retomada da política africana de densidade societal e mecanismos de penetração no tecido mais vivo da sociedade civil brasileira;

- a criação de novas linhas diretas de aviação de São Paulo, Rio de Janeiro e Brasília para capitais africanas como Lagos e Dacar, ademais das já existentes para Luanda, Pretória e Praia;

- a criação de uma logística náutica, especialmente a baratear fretes diretos entre o litoral brasileiro e o africano, sem passar pelos portos europeus ou norte-americanos;

- o desenvolvimento de joint-ventures entre empresas portuguesas e brasileiras que já trabalham juntas em várias áreas no Brasil e em Portugal, a utilizar a plataforma empresarial já existente e ampliada pelo ambiente da CPLP, de forma a fazer avançar parcerias com grupos econômicos africanos, dentro e fora do espaço da língua portuguesa 
na África, mas também a valorizar a língua de Camões na África, como fator de diversidade que representa;

- a criação de um grupo de contato estratégico do Brasil, a envolver não apenas diplomatas, mas os mais variados setores com experiência local e intelectual na África, com grupos estratégicos africanos e internacionais que trabalham nos projetos da NEPAD, no sentido do enfileirar posições e contribuições mútuas no que se refere à exploração da "brecha estrutural" no processo aberto pela tecnoburocracia internacional do Banco Mundial e do FMI;

- a criação imediata de programas de estudo, nas universidades e nas empresas, além da diplomacia, a respeito da África contemporânea, de forma a criar massa crítica sofisticada e conhecimento das realidades africanas em sua multiplicidade e a diminuir o grau de incompreensão e conhecimento vigentes no Brasil sobre o continente africano.

Essas sugestões são apenas o início de um longo caminho que terá que ser perseguido, pelo governo que se inaugura ou por qualquer outro que o suceda, uma vez que a África não pode mais suportar a indiferença dos seus vizinhos tão próximos. A história acumulada de contatos, mas também os desafios comuns para um futuro que chega rápido, estão a exigir respostas que tardam em chegar. Oxalá o Brasil não mais postergue sua inequívoca vocação africana.

Novembro de 2002

\section{Notas}

1 Várias análises, de diferentes escopos e objetivos, vêm participando desse esforço de leitura rigorosa da política externa do Brasil nos anos 1990 e início do novo século. Ver, por exemplo: CERVO, Amado Luiz. Relações internacionais do Brasil: um balanço da era Cardoso, Revista Brasileira de Política Internacional, 45 (1), p. 5-35, 2002.

2 Tradução desse esforço foi a articulação dos Reitores da Universidade de Buenos Aires (UBA), Universidade da República do Uruguai (UDELAR), da Universidade de Brasília (UnB) e da Universidade Nacional do Paraguai no dia 4 de julho de 2002, em Buenos Aires, no contexto da Décima-Nona Reunião Plenária da Comissão Parlamentar Conjunta do Mercosul, e do compromisso formalizado pelos quatro reitores no sentido de valorizar a discussão articulada das universidades com o meio social no sentido da valorização da dimensão social do Mercosul e dos intercâmbios de inteligências e de projetos de valorização da dimensão científica e tecnológica do processo de integração sub-regional. Ver UnB Notícias, 49 (5), p. 4, junho e julho de 2002. Ver, por exemplo, a inclusão dessa dimensão no trabalho preparatório da Universidade de Brasília ao processo eleitoral de 2002, quando o tema "Brasil e o mundo", com a contribuição conceitual e prática de estudiosos como Marco Aurélio Garcia, Samuel Pinheiro Guimarães, Amado Luiz Cervo, Oliveiros Ferreira, Cristovam Buarque, Roberto Freire, Luiz Pinguelli 
Rosa, Dércio Munhoz, entre outros, ganhou forte relevo nas discussões que duraram cerca de seis meses e que culminaram com a presença de candidatos à presidência da República nos debates organizados naquela instituição. Os termos dos debates estão publicados em dois volumes: MORHY, Lauro (org.). Brasil em questão: a universidade e a eleição presidencial. Volumes 1 e 2. Brasília: Editora UnB, 2002.

4 Esse trecho da entrevista de Ciro Gomes à Revista do Confea, agosto de 2002, página 7, demonstra o quanto a articulação entre os temas internos e externos estiveram imbricados de forma preponderante nos grande debates realizados. (itálicos do autor)

5 Ver, por exemplo, os artigos jornalísticos densos escritos nos últimos meses por pensadores à direita do espectro político como Delfim Netto ou mais à esquerda como Emir Sader ou José Luís Fiori, em vários jornais como a Folha de São Paulo, o Correio Braziliense, entre outros. Em comum, a crítica à vulnerabilidade externa do país e à necessidade de reconversão da inserção internacional do Brasil.

6 GARCIA, Marco Aurélio. PT negociará a ALCA. Correio Braziliense, Brasília, 25, outubro, 2002. Caderno Eleições 2002, p. 19.

7 Essa longa história de busca de contatos e afastamentos repentinos do Brasil em relação à África foi por mim analisada em vários estudos. Ver SARAIVA, José Flávio S. O lugar da África: a dimensão atlântica da política externa brasileira (de 1946 a nossos dias). Brasília: Editora da UnB, 1996. Ver também SARAIVA, José Flávio S. \& PANTOJA, Selma. Angola e Brasil nas rotas do Atlântico Sul. São Paulo: Bertrand Brasil, 1999. Ver, nessa mesma linha de estudos de caso, o estudo sobre a África do Sul: SARAIVA, José Flávio S. In: GUIMARÃES, Samuel Pinheiro. Brasil e África do Sul: riscos e oportunidades no tumulto da globalização. Análise comparada das políticas exteriores da África do Sul e do Brasil. Brasília: IPRI, 1997, p. 173-188.

8 SARAIVA, José Flávio S. In: SARAIVA, J. F. S. \& PANTOJA, S. Um momento especial nas relações Brasil-Angola: do reconhecimento da independência aos desdobramos atuais, op. cit., p. 225-254.

9 GARCIA, Marco Aurélio, op. cit., p. 19.

10 DÖPCKE, Wolfgang. Há salvação para a África? Thabo Mbeki e seu New Partnership For African Development. Revista Brasileira de Política Internacional, 45(1), p. 146-155, 2002.

11 Ver, sobre a idéia de “dança de paradigmas”, o artigo de CERVO, Amado Luiz, op. cit.

12 A idéia de "anos dourados” da política africana do Brasil foi por mim sugerida no livro já citado: SARAIVA, José Flávio S. O lugar da África, op. cit., capítulo quarto: “Os anos dourados da política africana (1967-1979)”, p. 125-184.

13 Veja as observações do Senador Roberto Freire, no contexto da campanha eleitoral, sobre a dimensão africana da brasilidade: "É nesse sentido que o conceito de brasilidade pode substituir a questão do nacionalismo. Brasilidade é uma afirmação muito mais cultural do que econômica, pois pode não ter o sentido de exclusão que o nacionalismo econômico tem, necessariamente, das fronteiras, da visão do mercado interno, da autarquização... O Estado brasileiro e suas instâncias políticas, sociais e econômicas apresentam desgraçadamente uma única cor, esmagadoramente branca. Isso não corresponde absolutamente à nossa realidade. Caber, portanto, dar à República a cor da vida e aí, não tenho dúvida, se destaca o negro.” FREIRE, Roberto. In MORHY, Lauro. Brasilidade: a superação do nacionalismo estreito , op. cit., p. 23 e 27.

14 COSTA E SILVA, Alberto da. A maninha e o libambo; a África e a escravidão, de 1500 a 1700. Rio de Janeiro: Nova Fronteira, 2002, p.11.

15 Essa idéia de "brechas estruturais” foi por mim sugerida, no Palácio Itaramarty, em seminário preparatório à Quarta Reunião de Chefes de Estado e de Governo da Comunidade dos Países de Língua Portuguesa (CPLP) em junho de 2002. Ver SARAIVA, José Flávio S. O diálogo Sul-Sul 
e a CPLP. Globalização e desigualdade no mundo pós-11 de setembro. In: MRE/DAOP-IPRI. CPLP: oportunidades e perspectivas. Brasília: FUNAG/IPRI, 2002, p. 309-328.

EGBUSON, Josef Sookore, "Brazil and Africa: opportunities and challenges”. Discurso proferido no Seminário Internacional: “Brasil e África: o lugar da NEPAD”, Auditório da Reitoria da Universidade de Brasília, 22 de outubro de 2002. (documento não impresso)

17 Ver essa contradição entre “política global” e “opções seletivas” do Brasil na África no último capítulo do meu livro: SARAIVA, José Flávio S. In: O lugar da África. A política africana dos anos 1990: a opção seletiva. Op. cit., cap. 6, p. 217-239.

18 Observar que a noção de "Estado logístico” foi amplamente defendida por Cervo, no artigo citado, e expõe a vontade de fortalecer o núcleo nacional da ação externa do Brasil, a transferência à sociedade da responsabilidade empreendedora, ajudando-a a atuar no ambiente externo e a busca por um melhor modo para equilibrar os benefícios da interdependência por meio de uma inserção madura no mundo globalizado.

\section{Bibliografica básica}

CERVO, Amado Luiz. Relações internacionais do Brasil: um balanço da era Cardoso. Revista Brasileira de Política Internacional. Brasília, 45(1), p. 5-35, 2002.

COSTA E SILVA, Alberto da. A manilha e o limbambo: a África e a escravidão, de 1500 a 1700 . Rio de Janeiro: Nova Fronteira, 2002.

DÖPCKE, Wolfgang. Há salvação para a África? Thabo Mbeki e seu New Partnership For African Development. Revista Brasileira de Política Internacional. Brasília, 45(1), p. 146-155, 2002.

FEIJÓ SOBRINHO, Pedro da Silva. Comunidade dos Países de Língua Portuguesa. Institucionalização e relações culturais, políticas e econômicas. Rio de Janeiro: Revan, 1997.

MOREIRA, Adriano (org.) Comunidade dos Países de Língua Portuguesa. Lisboa: Almedina Instituto Português da Conjuntura Estratégica, 2002.

PIMENTEL, José Vicente. As relações entre o Brasil e a África subssárica. Revista Brasileira de Política Internacional, 43(1), p. 5-23, 2000.

SARAIVA, José Flávio Sombra. O Lugar da África: a dimensão atlântica da política externa brasileira (de 1946 a nossos dias). Brasília: Editora da UnB, 1996.

SARAIVA, José Flávio Sombra (org.). Comunidade dos Países de Língua Portuguesa: solidariedade e ação política. Brasília: Instituto Brasileiro de Relações Internacionais, 2001.

SARAIVA, José Flávio Sombra; PANTOJA, Selma (org.) Angola e Brasil nas rotas do Atlântico Sul. Rio de Janeiro: Bertrand Brasil, 1999.

SARAIVA, José Flávio Sombra. O diálogo Sul-Sul e a CPLP: Globalização e desigualdade no mundo pós-11 de setembro. In: Departamento de África e Oriente Próximo; IPRI. CPLP: Oportunidades e perspectivas. Brasília: FUNAG/IPRI, 2002, p. 309-328.

\section{Resumo}

Este artigo discute as perspectivas para a política africana do Brasil tendo como base as últimas eleições presidenciais. Ao contrário do governo de Fernando Henrique Cardoso, espera-se que o governo Lula renove a política externa brasileira e restabeleça os contatos perdidos com o continente africano ao longo da última década. Por fim, há a exposição dos principais motivos para o relançamento da política africana do Brasil. 
Abstract

This article discusses the perspectives of the African policy of Brazil based on the last presidential elections. Unlike Fernando Henrique Cardoso's government, it is expected that Lula will renew the Brazilian foreign policy and reestablish the lost contacts with the African continent during the last decade. At the end, there is an exposition of the main reasons to reintroduce the African policy of Brazil.

Palavras-chave: África; Política Africana do Brasil; Política Externa do Brasil. Key words: Africa; African Policy of Brazil; Brazilian Foreign Policy. 